Count words : 10’188

\title{
Parametric Experimental Study and Design of Eperiment Modelling of Sapphire Grinding
}

\author{
K. Wasmer ${ }^{1, * \dagger}$, P.-M. Pochon ${ }^{2 \dagger}$, D. Sage ${ }^{3}$ and J.H. Giovanola ${ }^{2}$ \\ ${ }^{1}$ Empa, Swiss Laboratories for Materials Science \& Technology, Laboratory for \\ Advanced Materials Processing, Feuerwerkerstrasse 39, CH-3602 Thun, Switzerland \\ ${ }^{2}$ Ecole Polytechnique Fédérale de Lausanne (EPFL), CH-1015 Lausanne, Switzerland \\ ${ }^{3}$ Ecole Polytechnique Fédérale de Lausanne (EPFL), Biomedical Imaging Group (BIG), \\ CH-1015 Lausanne, Switzerland
}

\begin{abstract}
:
This study investigates and models the grinding process of single crystal sapphire. Five parameters: the wheel speed, the feed speed, the vertical feed, the ultrasonic assistance and the crystallographic direction were considered via a design of experiments (DoE) approach. The responses were multiple but can be divided in three groups: the process, the machine and the grinding quality. DoE results revealed that the parameters interact in a complex manner and depends on the responses. Therefore, to gain a better understanding of the grinding process of sapphire, the interactions between parameters have also to be taken into consideration. It was found that three main parameters have the largest influences on the tangential grinding forces: the wheel speed, the feed speed and the vertical feed. In contrast, the median defect area is mainly impacted by the quadratic effects of the wheel speed and vertical feed followed by various interactions. After an optimization procedure, the second optimum for the tangential forces was found to be very close to the best optimum for the median defect area. The optimum solution is: a wheel speed of 7'500 $\mathrm{rpm}$, a feed speed of $60 \mathrm{~mm} / \mathrm{min}$, a vertical feed of $12.5 \mu \mathrm{m} /$ pass, no ultrasonic assistance and grinding along the $c$-axis. This set of parameters was validated with additional and repeated tests on both Verneuil and Kyropouloas sapphire. Finally, it came out that the optimum solution has also a very good productivity.
\end{abstract}

Keywords: grinding, sapphire, ultrasonic assistance, design of experiments.

* Corresponding author: Kilian Wasmer; Tel: +41 5876562 71; Fax: +41 5876569 90; E-mail: kilian.wasmer@empa.ch

$\dagger$ Both authors have contributed equally to this work. 


\section{1) INTRODUCTION}

This paper presents an investigation of the grinding of narrow (approximately $0.45 \mathrm{~mm}$ wide x $0.45 \mathrm{~mm}$ deep) grooves in sapphire by means of a parametric experimental approach using the Design of Experiments (DoE) methodology. To guarantee the functional suitability of the finished product, the process of grinding these grooves in sapphire must meet the imposed geometrical and dimensional specifications; in particular it must preserve the sharpness of the surface edges of the groove and minimize any other collateral damage, such as median or lateral cracks at the bottom of the groove. To help meeting these requirements, while still achieving economically acceptable material removal rates, the effect of superimposed ultrasonic vibrations was also considered in this study.

To meet these requirements while achieving economically acceptable grinding times, we performed grinding experiments with a modified CNC 3-axes milling machine. The samples with ground grooves were analyzed using an image analysis program specifically developed to quantify various types of encountered defects. The quantified defects were then used to develop several semi-empirical models based on a $2^{5-1}$ fractional factorial DoE. The models served to characterize and optimize the grinding process in terms of groove quality and process efficiency. The set of optimized process parameters were validated on the basis of independent experiments. We also discussed the process models and the established optimum process parameters on the basis of contact and fracture mechanics principles to gain a more fundamental understanding of the sapphire grinding process.

Grinding is one of the oldest processes for processing/shaping hard materials and has been the subject of numerous investigations (Groover, 2010; Malkin, 1989). Yet, the influence of the many parameters affecting the process still remains poorly understood and modeled. The first attempts at characterizing the material removal rate $(M R R)$ during grinding involved purely geometric/kinematics modeling for estimating the maximum chip thickness. The kinematics model of (Groover, 2010; Malkin, 1989) considers dependencies between the grinding wheel microstructure, the amplitude of the wheel-work piece relative motions, and the geometry of the grinding wheel. Although this is a simplified and idealized approach, it plays a major role in predicting surface quality (Agarwal and Rao, 2010; Mayer and Fang, 1995) and evaluating the material removal efficiency of the process (Agarwal and Rao, 2010). Because grinding involves material deformation and 
fracture and because some of its parameters unavoidably evolve with time, grinding models must consider the effect of applied forces and of tool wear, which significantly adds to their complexity. More advanced models assume that material removal occurs by microcracking (median and lateral cracks) and generation of chip fragments (Evans and Marshall, 1980; Malkin and Hwang, 1996; Marinescu et al. 2000). Energy considerations such as those first proposed by Preston in (1927) provide another approach for developing simple grinding models. Inasaki (1987) suggested using the specific grinding energy, $E$, as a characterizing parameter. In his model, which also incorporates a geometric/kinematics model, the specific grinding energy is expressed in terms of the tangential grinding force, the peripheral velocity of the grinding wheel, the workpiece translational velocity, the depth of cut and the width of the grinding wheel.

During the past decade, industrial needs have prompted many efforts in mechanistic modelling, simulation and even probabilistic modelling of grinding processes (Brinksmeier et al., 2006; Stepien, 2009). Unfortunately, none of these models is detailed and reliable enough to allow a model-based optimization of the industrial grinding process.

Ultrasonic assistance (USA) significantly changes the grinding mechanisms activated during the cutting process (Uhlmann and Spur, 1998). USA superimposes a vibratory motion on the conventional grinding kinematics. Benefits of USA to grinding include:

- A reduction of loads on the grinding tool and consequently of its wear rate (Brehl and Dow, 2008).

- A better surface quality for the workpiece with less sub-surface damages $(\mathrm{Qu}$ and al., 2000).

- An increased material removal rate (Pei and al., 1995).

Grinding is a process best suited for hard materials. The nature of the material of the workpiece greatly influences the mechanisms of chip formation and the resulting surface quality of ground parts (Tönshoff et al., 1992). Although numerous studies have been conducted to understand and model the behavior of brittles solids, such as glasses and polycrystalline ceramics, the literature is less comprehensive for single crystal sapphire. Experiments were performed on single crystal sapphire and showed a strong correlation between the Preston's coefficient and the workpiece roughness (Funkenbusch et al., 1998). More recently, classical types of surface deformations induced by abrasive machining, such as lattice deformation, strain and scratch were studied on sapphire wafer (Wen et al., 
2008). Kim et al. (2003) demonstrated that maintaining the feeding force constant, instead of the feeding rate, allows minimizing defects in sapphire. Fundamental characterization of the material in (Inkson, 2000) highlighted peculiar behaviors during twinning or microcracking in $\mathrm{Al}_{2} \mathrm{O}_{3}$. These focused studies for specific materials do not provide a comprehensive understanding of the effect on grinding of various properties such as anisotropy of the sapphire, Young's modulus $(E)$, fracture toughness $K_{I c}$, and strength $\left(\sigma_{c}\right)$, and sapphire production methods (Verneuil, EFG, and Kyropulos).

Section 2 of this paper presents the experimental procedure used for the investigation (USA grinding set-up, material used, defect analysis procedure), the DoE quadratic model, as well as the various responses analyzed.

Section 3 discusses the correlation between the process parameters; grinding forces and finished groove quality are selected as key process indices and the corresponding DoE models are then proposed and optimized. The two optimized models serve to determine the best optimum for the process parameters. We show that the optimum in terms of grinding force and material quality are very similar. Finally, the optimum model is validated by performing additional tests and comparing the new results to the results of all experiments. The validation is performed not only for the grinding forces and material quality but also for the specific material removal rate and the total processing time.

Section 4 discusses the models and their optimization based on contact mechanics and fracture mechanics principles.

Section 5 summarizes the findings of the investigation and shows that optimized grinding parameters can be selected that satisfies both surface quality and material removal rate requirements.

\section{2) EXPERIMENTAL PROCEDURES AND MATERIALS TESTED}

\subsection{Experimental setup and procedure}

Figure 1 shows the experimental set-up used in the investigation, a modified CNC 3axes milling machine. In this set-up, the spindle with the grinding disk has the three translational degrees of freedom $x, y$ and $z$, whereas the workpiece is stationary (Fig. 1a). An asynchronous electric motor drives the precision spindle by means of pulleys and a belt at speeds ranging from 1'000 to 22 ' $000 \mathrm{rpm}$.

Experiments can be carried out with or without ultrasonic assistance (USA). The machine includes the following instrumentation: 
1) Rotary encoders on the motors of the axes, from which the $x, y$ and $z$ motions can be derived;

2) An encoder to measure the rotational speed of the spindle;

3) A torque meter, mounted by means of two balanced flexible couplings between the spindle and the belt-and-pulley transmission to measure the grinding torque;

4) A waterproof dynamometric table to measure the thrust grinding force, from now on referred to as normal force ${ }^{1}$.

Figure $1 \mathrm{~b}$ shows the arrangement used in experiments with USA. The specimen is glued on a holder mounted directly on the tip of the sonotrode generating the ultrasonic axial motion $^{2}$. The US actuator consists of a Branson piezoelectric converter excited by an ultrasonic generator (Branson type $2000 \mathrm{~b} / \mathrm{bdc}$ ). The converter generates an axial sinusoidal motion with a controlled frequency of $20 \mathrm{kHz}$ and is coupled to a booster designed to have a zero axial displacement node at the resonant frequency of $20 \mathrm{kHz}$ and an amplification factor of 1,48 . The displacement node on the booster permits mounting of the sonotrode system without transmission of deleterious vibrations to the rest of the CNC machine. This arrangement achieved a peak to peak maximum displacement of the specimen of about $33 \mu \mathrm{m}$. In experiments with USA, we did not measure the normal grinding force to avoid vibration damage to the dynamometric table.

Figure 1c shows the experimental configuration for tests without USA. In this case, the sapphire specimen is glued on the dynamometric table, which itself is bolted onto the support base and the fluid recuperation tank.

\footnotetext{
${ }^{1}$ Forces are measured with three subminiature sensors (XCF 205R from Measurement Specialties) placed in a triangular pattern underneath the platen of the table. Each sensor provides a measurement range between 0 and $20 \mathrm{~N}$ and a high rigidity of $9 \cdot 10^{6} \mathrm{~N} / \mathrm{m}$.

${ }^{2}$ The holder is mounted to the sonotrode with a bolt that allows an appropriate preload to avoid interface separation. A high strength glue is required to avoid spalling off of the specimen from the holder.
} 



b)

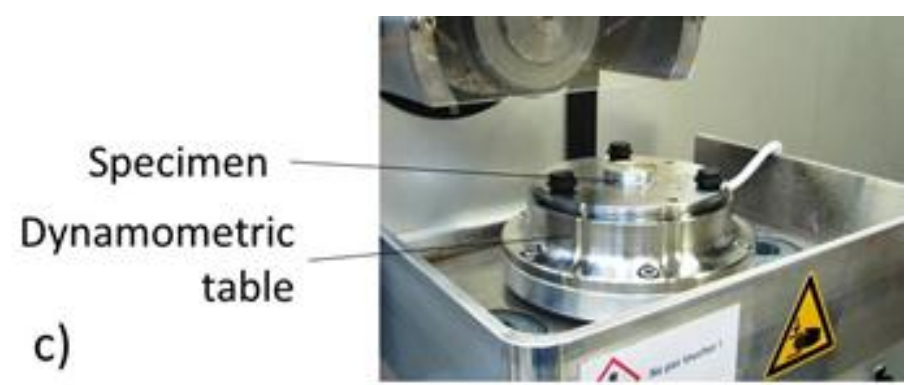

Figure 1: Photographs of the experimental setup a) overall view of the grinding machine, b) configuration for grinding with USA but without thrust force measurement, c) configuration for grinding without USA and with thrust force measurement. 
The experiment consists of grinding parallel grooves of square cross section (roughly $0.45 \mathrm{~mm} \times 0.45 \mathrm{~mm}$ ) on the surface of the disk-like single crystal sapphire specimens using a $75 \mathrm{~mm}$ diameter, $0.43 \mathrm{~mm}$ copper-tin wheel charged with an oblong, splintershaped grit of mono-crystalline diamond grains (grain size: 20-40 $\mu \mathrm{m}$ ). A coolant supply system (see Figs 1a and 1b) provides lubrication to the wheel and specimen and their interface. Before each set of experiments on a new specimen, we sharpened the grinding wheel on a dressing stone or we replaced it by a new one if it had been damaged or excessively worn. When mounting a new wheel, concentricity of the wheel and the spindle, as well as axial run-out of the wheel, were carefully controlled and kept within 5 $\mu \mathrm{m}$.

During the experiments without USA, we measured the torque applied to the spindle, the normal grinding force and the table motion. As mentioned above, during the experiments with USA, we only measured the spindle torque and the table motion.

We estimated the tangential grinding force from the spindle torque measurements by dividing it by the outer radius of the grinding wheel.

\subsection{Material}

We performed tests on polished mono-crystalline sapphire samples produced by the Kyropoulos and Verneuil methods and cut into cylinders with a $30 \mathrm{~mm}$ diameter and a thickness of $3 \mathrm{~mm}$. The $a$-plane of the crystal corresponded with the surface of the specimen and grinding occurred along the $c$ - or $m$-directions (See Fig. 2). X-ray measurements established that the $a$-direction had a maximum misorientation angle of $1^{\circ}$ with respect to the crystal growing direction

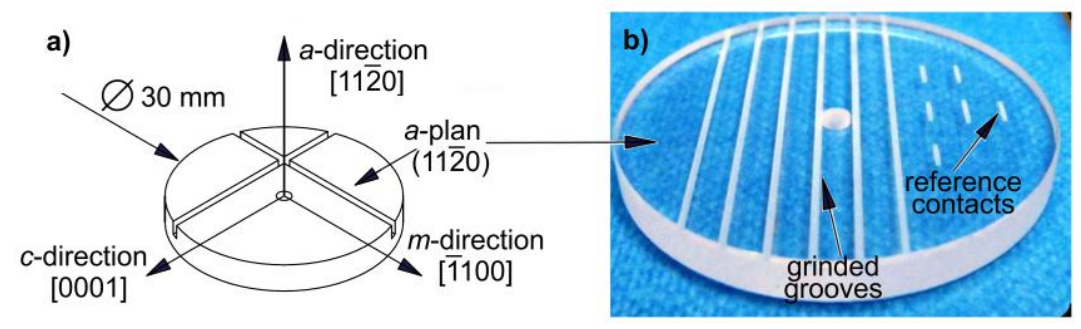

Figure 2: (a) Schematic of the sapphire samples including the grinding directions and (b) example of a sample grinded along the $c$-direction with the reference contacts for the grinding wheel. 


\subsection{Analysis of Grinding Defects}

Defects at the surface edges of the groove (See Figure 3) often represent the most detrimental grinding damage. Therefore, in the present investigation, we focused on this category of chipping defects caused by the intersection of lateral and radial cracks (Ahn et al., 1998; Lawn et al., 1980, Lawn, 1997; Marshall et al., 1982, Wasmer et al., 2005; Wasmer et al., 2008a; Wasmer et al., 2013).

The defect analysis procedure entails several steps. First, dark field optical images are taken and processed by an image analysis software to facilitate feature recognition. The enhanced images are then treated to extract quantifiable values of characteristic geometric parameters of the defects.

The images of the groove were taken using a Zeiss Axioplan microscope equipped with a CCD camera ProgRes ${ }^{\circledR}$ C14 from Jenoptik. For reliable data analysis, 20 images with a $50 \mathrm{X}$ magnification were taken and stitched together to have a characterized groove length of over $17.5 \mathrm{~mm}$. Figure 3 shows an image of one groove with defects (Fig. 3a) and how these defects are recognized and quantified (Fig. 3b).

The defect images were processed with ImageJ, a free, multi-platform, open-source software package (Unser et al., 1989). To capture the fine details of the defects, we developed our own ImageJ plugin. The plugin of this contribution is made freely available at: http://XXX/ (it will put online after acceptation of the paper).

To have sufficient control on the global smoothness on the contour, a shortest-path method was chosen to extract the border of the defects. The edge detection is carried out via an optimization procedure running in the groove direction over the whole image. The unit cost function $\zeta_{k, k+1}$ from the column $k$ to the column $k+1$ of the image is defined by:

$$
\zeta_{k, k+1}=\lambda_{i} \cdot\left(f_{\max }-f\left(x_{k}, y_{k}\right)\right)+\lambda_{d} \cdot\left|y_{k}-y_{k+1}\right|
$$

where $f(x, y)$ is the intensity value at the coordinate $(x, y)$, and $\lambda_{i}$ and $\lambda_{d}$ are two weighted factors. By tuning these weights, one can easily adapt to various types of images and control the trade-off between smoothness and accuracy. The procedure is fast enough to allow a user interaction to force the curve to pass through some specific positions. 

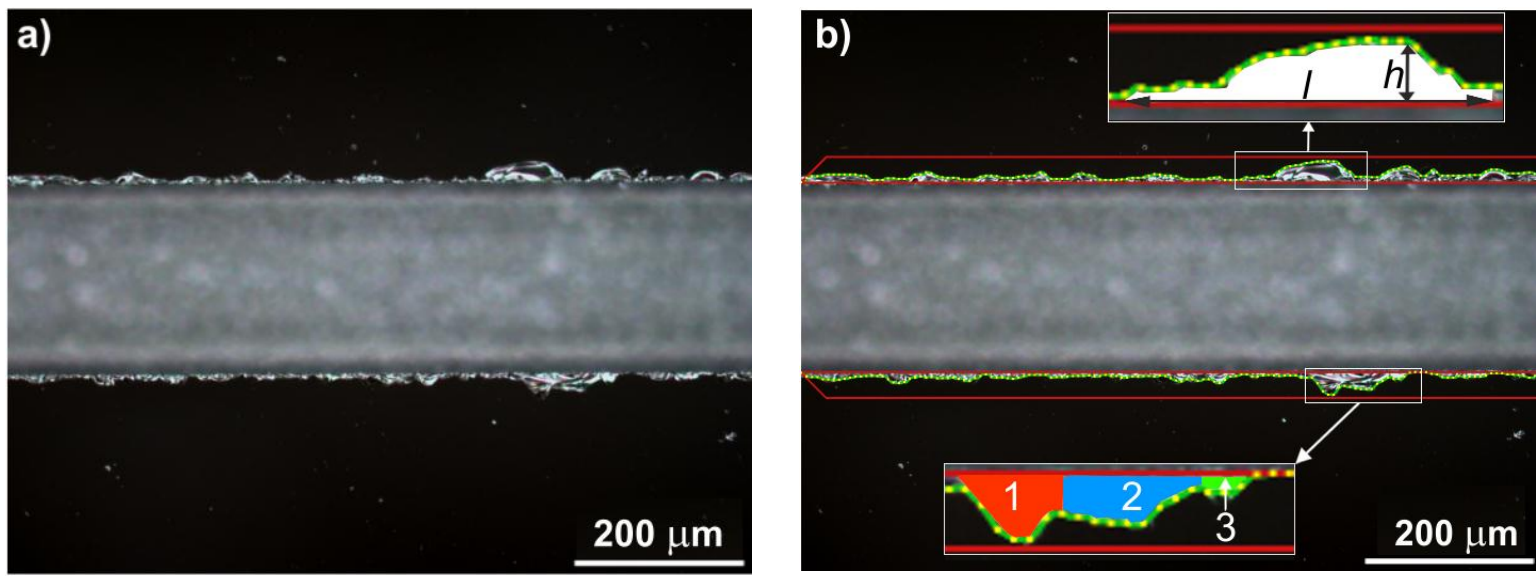

Figure 3: Dark field images of the top view of a groove taken with an optical microscope. a) raw image and b) image analyzed with ImagJ using a specific subroutine delineating the defects. (The enlarged view provides examples of defect detections and measurements.

The final step consists in extracting quantifiable characteristic parameters from the image analysis. We developed a program to determine the length $(l)$, height $(h)$ and area $(A)$ of each defect as shown in Fig. 3b. The minimum defect height measured was as low as 1 $\mu \mathrm{m}$. Many other parameters related to the height and area of the defects can also be extracted from the image analysis data and the complete list is given in Table 5 in Section 2.5. These extracted parameters are potential candidates for prediction by the DoE analysis, i.e. are candidate responses for the DoE analysis.

\subsection{Definition of Parameters Characterizing Productivity}

A minimum level of productivity is required for a process to be industrially viable. Therefore, two parameters are considered for the characterizing the process productivity: the specific material removal rate and total processing time. The specific material removal

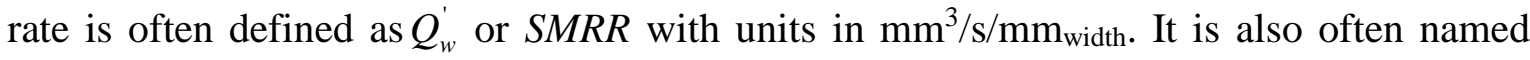
material removal rate per unit active grinding wheel width which has unit in $\mathrm{mm}^{2} / \mathrm{s}$. SMMR is given by (Malkin, 1989):

$$
S M M R=Q_{w}^{\prime}=v_{a} \cdot a_{e}
$$

where $v_{a}$ is the feed speed and $a_{e}$ is the depth of cut. Eq. (2) permits a direct comparison of various grinding processes with respect to productivity, as well as an evaluation of the actual removal capacity. Clearly from Eq. (2), the SMMR has the benefit of being very easy to estimate since it is governed only by the feed speed and the depth of cut $a_{e}$. 


\subsection{Design of Experiment (DoE) Approach}

A large number of factors may potentially influence the grinding quality. They can be divided into five groups: (1) process parameters, (2) materials, (3) machine, (4) grinding wheel, and (5) human factors. Each group can be divided into sub-groups, e.g. process parameters include the wheel speed, the feed speed, the vertical feed, etc... Hence, a total of 31 factors were inventoried (not shown here). To establish which of these factors most strongly affect the quality of the ground groove, we adopt the DoE approach described below. For a general discussion of DoE methodologies, the reader can consult references (Box et al., 1978; Montgomery, 2009).

We first assume that interactions between the various factors have a significant influence on the results. Therefore, a two-level fractional factorial design or $2^{k}$ factorial design has been chosen in this work. Such $2^{k}$ factorial designs are widely used when factor screening experiments are required (Box et al., 1978). Here, $k$ corresponds to the number of factors, which can each have 2 levels. Considering all 31 factors has two drawbacks. First, a two-level full factorial design requires over two billion tests (precisely $2^{31}$ runs) a number of tests we can obviously not perform. Second, the model would be extremely complex with many parameters and most of them would have limited to no impact on the grinding process. Consequently, only five parameters, which we consider as the most important ones, are taken into account. These parameters are listed in Table 1. Other parameters such as the machine, the grinding wheels and the human factors were kept constant to minimize their impacts.

\begin{tabular}{|c|c|c|c|c|c|c|}
\hline Controlled factor & Unit & Type & Code & Min $(-1)$ & Centre $(0)$ & Max $(+1)$ \\
\hline Wheel speed & {$[\mathrm{m} / \mathrm{s}]$} & Quantitative & $x_{1}$ & 2 & 16 & 30 \\
\hline Feed speed & {$[\mathrm{mm} / \mathrm{min}]$} & Quantitative & $x_{2}$ & 60 & 230 & 400 \\
\hline Vertical feed & {$[\mu \mathrm{m} / \mathrm{pass}]$} & Quantitative & $x_{3}$ & 2 & 11 & 20 \\
\hline Ultrasonic assistance & & Logical & $x_{4}$ & No & & Yes \\
\hline $\begin{array}{c}\text { Crystallographic } \\
\text { direction }\end{array}$ & & Qualitative & $x_{5}$ & $m$-axis & & $c$-axis \\
\hline
\end{tabular}

Table 1: Grinding parameters for the experiments performed on Verneuil sapphire.

A series of preliminary tests was performed to define the minimum and maximum values of the selected factors, to ensure reproducibility and the likely significance of the results. We performed screening experiments using a 12-run Plackett and Burman design to estimate the main trends. Such multifactorial designs are useful to screen a large number of factors with a minimum of experiments (Box et al., 1978). The results of the first 
screening experiments (all together 82 pre-tests) provided confidence in the chosen basis for further modelling.

A full factorial design based on Table 1 would require at least 108 experiments. To reduce the number of experiments, we selected a fractional factorial design with a resolution $R=V$ proposed by Box et al. (1978). When selecting a fractional design, it is important to consider the concept of the resolution $R$. This concept indicates which levels of interaction are aliased. With this design of resolution, every main effect $a_{i}$ is aliased with a four-factor interaction coefficient (e.g. $a_{i}+a_{i j k l}$ ) and every two-factor interaction is aliased with a third-factor interaction (e.g. $a_{i j}+a_{i j k}$ ) (Box et al., 1978; Montgomery, 2009). Consequently, a $2^{k}$ factorial design of resolution $R=V$ provides a unique estimation of the main effects and the two-factor interaction effects.

Using this approach, a fractional factorial design with $2_{V}^{(5-1)}=2_{V}^{4}=16$ runs was planned, even thought 16 alias sets are introduced when considering all possible interactions. The sets of contrasts were defined by the generator $5=1234$ (Box et al., 1978; Montgomery, 2009). The experiment matrix $X$ for a $2^{4}$ design is presented in Table 2 (Box et al., 1978; Montgomery, 2009). Only two levels of variations $(-1$ and +1$)$ are used for all parameters in Table 1. To avoid any bias in the model, the second and higher order interactions are neglected.

\begin{tabular}{|c|c|c|c|c|c|c|c|c|c|c|c|c|c|c|c|c|c|}
\cline { 2 - 19 } \multicolumn{1}{c|}{} & $I$ & $x_{5}$ & $x_{4}$ & $x_{3}$ & $x_{2}$ & $x_{1}$ & \multicolumn{1}{c|}{ Interactions } \\
\hline Run & $a_{0}$ & $a_{5}$ & $a_{4}$ & $a_{3}$ & $a_{2}$ & $a_{1}$ & $a_{12}$ & $a_{13}$ & $a_{14}$ & $a_{15}$ & $a_{23}$ & $a_{24}$ & $a_{25}$ & $a_{34}$ & $a_{35}$ & $a_{45}$ \\
\hline 1 & +1 & -1 & -1 & -1 & -1 & +1 & -1 & -1 & -1 & -1 & +1 & +1 & +1 & +1 & +1 & +1 \\
\hline 2 & +1 & -1 & -1 & -1 & +1 & -1 & -1 & +1 & +1 & +1 & -1 & -1 & -1 & +1 & +1 & +1 \\
\hline 3 & +1 & -1 & -1 & +1 & -1 & +1 & +1 & -1 & +1 & +1 & -1 & +1 & +1 & -1 & -1 & +1 \\
\hline 4 & +1 & -1 & -1 & +1 & +1 & -1 & +1 & +1 & -1 & -1 & +1 & -1 & -1 & -1 & -1 & +1 \\
\hline 5 & +1 & -1 & +1 & -1 & -1 & +1 & +1 & +1 & -1 & +1 & +1 & -1 & +1 & -1 & +1 & -1 \\
\hline 6 & +1 & -1 & +1 & -1 & +1 & -1 & +1 & -1 & +1 & -1 & -1 & +1 & -1 & -1 & +1 & -1 \\
\hline 7 & +1 & -1 & +1 & +1 & -1 & +1 & -1 & +1 & +1 & -1 & -1 & -1 & +1 & +1 & -1 & -1 \\
\hline 8 & +1 & -1 & +1 & +1 & +1 & -1 & -1 & -1 & -1 & +1 & +1 & +1 & -1 & +1 & -1 & -1 \\
\hline 9 & +1 & +1 & -1 & -1 & -1 & +1 & +1 & +1 & +1 & +1 & +1 & +1 & -1 & +1 & -1 & -1 \\
\hline 10 & +1 & +1 & -1 & -1 & +1 & -1 & +1 & -1 & -1 & -1 & -1 & -1 & +1 & +1 & -1 & -1 \\
\hline 11 & +1 & +1 & -1 & +1 & -1 & +1 & -1 & +1 & -1 & -1 & +1 & -1 & +1 & -1 & +1 & -1 \\
\hline 12 & +1 & +1 & -1 & +1 & +1 & -1 & -1 & -1 & +1 & +1 & +1 & -1 & +1 & -1 & +1 & -1 \\
\hline 13 & +1 & +1 & +1 & -1 & -1 & +1 & -1 & -1 & +1 & +1 & +1 & -1 & -1 & -1 & -1 & +1 \\
\hline 14 & +1 & +1 & +1 & -1 & +1 & -1 & -1 & +1 & -1 & -1 & -1 & +1 & +1 & -1 & -1 & +1 \\
\hline 15 & +1 & +1 & +1 & +1 & -1 & +1 & +1 & -1 & -1 & -1 & -1 & -1 & -1 & +1 & +1 & +1 \\
\hline 16 & +1 & +1 & +1 & +1 & +1 & -1 & +1 & +1 & +1 & +1 & +1 & +1 & +1 & +1 & +1 & +1 \\
\hline
\end{tabular}

Table 2: Matrix of runs $X$ for a $2_{V}^{4}$ design (Box et al., 1978; Montgomery, 2009) 
When interaction terms are added to the model, the model may be subjected to quadratic effects or second order curvature (Montgomery, 2009). Under such circumstances, adding center points is frequently advised to verify the model for curvature which requires additional experiments. This is made by using a center point for the factors $x_{1}, x_{2}$ and $x_{3}$. There are various possibilities to define and combine the new additional experiments. They are determined by performing numerical tests using two criteria proposed by Box et al. (1978). First, the DoE is best when the dispersion matrix $\left(X^{T} X\right)^{-1}$ is minimal. Second, the effects of the considered parameters have to be estimated as independently as possible (orthogonality of the matrix and symmetry of the runs). This approach leads to eight additional runs that are listed in Table 3. A matrix [24 x 19] is obtained by combining the experiments of Tables 2 and 3. This matrix allows having a model with 19 degrees of freedom.

\begin{tabular}{|c|c|c|c|c|c|}
\cline { 2 - 6 } \multicolumn{1}{c|}{} & $x_{5}$ & $x_{4}$ & $x_{3}$ & $x_{2}$ & $x_{1}$ \\
\hline Run & $a_{5}$ & $a_{4}$ & $a_{3}$ & $a_{2}$ & $a_{1}$ \\
\hline 17 & -1 & -1 & 0 & 0 & 0 \\
\hline 18 & -1 & -1 & 0 & 0 & 0 \\
\hline 19 & +1 & +1 & +1 & 0 & 0 \\
\hline 20 & +1 & -1 & 0 & 0 & +1 \\
\hline 21 & -1 & +1 & 0 & 0 & 0 \\
\hline 22 & +1 & +1 & -1 & -1 & 0 \\
\hline 23 & +1 & -1 & 0 & 0 & -1 \\
\hline 24 & -1 & +1 & 0 & & 0 \\
\hline
\end{tabular}

Table 3: Additional runs for the matrix $X$

Although many process parameters were fixed, we cannot ignore that they may be subjected to drift. To minimize this effect, it is crucial to perform the 24 runs randomly. The orders of the runs were obtained with a random number generator and are given in Table 4. To check the repeatability of the tests, each condition was tested twice.

\begin{tabular}{|c|c|c|c|c|c|c|c|c|c|c|c|c|c|c|c|c|c|c|c|c|c|c|c|c|}
\hline Order run 1 & 17 & 1 & 11 & 6 & 2 & 23 & 12 & 9 & 3 & 24 & 16 & 20 & 22 & 21 & 14 & 10 & 18 & 13 & 19 & 8 & 4 & 15 & 5 & 7 \\
\hline Order run 2 & 22 & 6 & 3 & 16 & 11 & 7 & 17 & 14 & 8 & 5 & 21 & 19 & 15 & 1 & 23 & 2 & 4 & 18 & 24 & 13 & 9 & 20 & 10 & 12 \\
\hline 1
\end{tabular}

The responses modeled with the DoE approach can be divided into three groups: the process, the machine and the material quality. The details are given in Table 5. Expanding each group leads to a large number of responses and so of potential models. 


\begin{tabular}{|c|c|c|c|}
\hline Name of the responses & Unit & Type & Abbreviations \\
\hline \multicolumn{4}{|c|}{ Process responses } \\
\hline Machining time & {$[\mathrm{s}]$} & Quantitative & $t$ \\
\hline Specific material removal rate & {$\left[\mathrm{mm}^{2} / \mathrm{s}\right]$} & Quantitative & $S M R R$ or $Q_{w}^{\prime}$ \\
\hline Equivalent chip thickness & {$[\mu \mathrm{m}]$} & Quantitative & $h_{e q}$ \\
\hline Maximum chip thickness & {$[\mu \mathrm{m}]$} & Quantitative & $h_{\operatorname{Max}}$ \\
\hline \multicolumn{4}{|c|}{ Machine responses } \\
\hline Tangential grinding force & {$[\mathrm{N}]$} & Quantitative & $F_{c}$ \\
\hline Equivalent increase in grinding force (normal force) & {$[\mathrm{N}]$} & Quantitative & $F_{n}$ \\
\hline \multicolumn{4}{|c|}{ Material quality responses } \\
\hline Number of defects per mm & {$[1 / \mathrm{mm}]$} & Quantitative & $d_{m m}$ \\
\hline Number of defects & & Quantitative & $d_{N^{\circ}}$ \\
\hline Maximum defect height & {$[\mu \mathrm{m}]$} & Quantitative & $h_{\operatorname{Max}}$ \\
\hline Median defect height & {$[\mu \mathrm{m}]$} & Quantitative & $h_{\text {Median }}$ \\
\hline Mean defect height & {$[\mu \mathrm{m}]$} & Quantitative & $h_{\text {Mean }}$ \\
\hline Total defect area & {$\left[\mu \mathrm{m}^{2}\right]$} & Quantitative & $A_{\text {Tot }}$ \\
\hline Maximum defect area & {$\left[\mu \mathrm{m}^{2}\right]$} & Quantitative & $A_{\operatorname{Max}}$ \\
\hline Median defect area & {$\left[\mu \mathrm{m}^{2}\right]$} & Quantitative & $A_{\text {Median }}$ \\
\hline Mean defect area & {$\left[\mu \mathrm{m}^{2}\right]$} & Quantitative & $A_{\text {Mean }}$ \\
\hline
\end{tabular}

Table 5: Process, machines and material quality responses

\subsection{The model}

As mentioned in Section 2.5, in this work, we do want to consider the quadratic effects. Consequently, the DoE associated with a quadratic model is defined the following equation:

$$
y=a_{0}+\sum_{1}^{N} a_{i} x_{i}+\sum_{1, i \neq j}^{N} a_{i j} x_{i} x_{j}+\sum_{1}^{3} a_{i i} x_{i}^{2}+e_{i}
$$

where $y$ is the response, $a_{0}$ represents the constant effect, $a_{i}$ the main effects, $a_{i j}$ the first order interaction effects, $a_{i i}$ the first order quadratic effects and $e_{i}$ the errors (also known as the residual). For each desired response, a least square algorithm is employed to estimate the coefficients of the model. The higher orders are neglected.

In agreement with the DoE presented in Section 2.5, this model has 19 degrees of freedom. The constitutive equation of the full model is:

$$
\begin{aligned}
y & =a_{0}+a_{1} x_{1}+a_{2} x_{2}+a_{3} x_{3}+a_{4} x_{4}+a_{5} x_{5}+a_{12} x_{1} x_{2}+a_{13} x_{1} x_{3}+a_{14} x_{1} x_{4}+a_{15} x_{1} x_{5} \\
& +a_{23} x_{2} x_{3}+a_{24} x_{2} x_{4}+a_{25} x_{2} x_{5}+a_{34} x_{3} x_{4}+a_{35} x_{3} x_{5}+a_{45} x_{4} x_{5} \\
& +a_{11} x_{1}^{2}+a_{22} x_{2}^{2}+a_{33} x_{3}^{2}
\end{aligned}
$$

Note that the error terms, included in the statistical model, are not written. In addition, only the variables $x_{1}, x_{2}$, and $x_{3}$ are continuous and can have a quadratic component. 
Equation 4 represents the relationship between process parameters and process response of the sapphire sample and is known as (multidimensional) processing map. Hence, the processing maps should define the combination of processing parameters (for a given manufactured geometrical detail) guaranteeing successful machining in the shortest time and most economic way.

\section{RESULTS}

\subsection{Introduction}

Table 1 listed 5 selected grinding parameters, whereas Table 5 contains 15 possible responses. Theoretically, a model for each response can be developed. The number of models can actually be minimized by making a judicious choice of responses. This can be done by considering the correlation coefficient between the responses. The correlation between the normal and tangential grinding force is 0.74 . This is lower than expected as both forces are often considered to be related. Nevertheless, despite the low value of the correlation, only the tangential force will be modeled and we will assume that normal and tangential force will be correlated, if only weakly.

The correlation matrix associated with the material quality is given in Table 6. Most responses in terms of defect heights $(h)$ and area $(A)$ are highly correlated and so very little differences are expected between those models. The number of defects per mm $\left(d_{m m}\right)$ and the number of defects $\left(d_{N^{o}}\right)$ are also highly correlated but interestingly, they are inversely correlated with the defect heights and areas. In other words, the larger the median defect area, the lower the number of defects. To eliminate the sensitivity to potential very large defects, a model is built using the median defect area response and it is compared with the median defect height for validation.

\begin{tabular}{|c|c|c|c|c|c|c|c|c|c|}
\cline { 2 - 9 } \multicolumn{1}{c|}{} & $d_{m m}$ & $d_{N^{\circ}}$ & $h_{\text {Max }}$ & $h_{\text {Median }}$ & $h_{\text {Mean }}$ & $A_{\text {Tot }}$ & $A_{\text {Max }}$ & $A_{\text {Median }}$ & $A_{\text {Mean }}$ \\
\hline$d_{m m}$ & 1.00 & & & & & & & & \\
\hline$d_{N^{\circ}}$ & 0.86 & 1.00 & & & & & & & \\
\hline$h_{\text {Max }}$ & -0.75 & -0.66 & 1.00 & & & & & & \\
\hline$h_{\text {Median }}$ & -0.73 & -0.75 & 0.82 & 1.00 & & & & & \\
\hline$h_{\text {Mean }}$ & -0.77 & -0.75 & 0.90 & 0.98 & 1.00 & & & & \\
\hline$A_{\text {Tot }}$ & -0.80 & -0.63 & 0.93 & 0.88 & 0.93 & 1.00 & & & \\
\hline$A_{\text {Max }}$ & -0.66 & -0.53 & 0.91 & 0.67 & 0.78 & 0.89 & 1.00 & & \\
\hline$A_{\text {Median }}$ & -0.84 & -0.76 & 0.89 & 0.90 & 0.94 & 0.96 & 0.85 & 1.00 & \\
\hline$A_{\text {Mean }}$ & -0.81 & -0.71 & 0.93 & 0.85 & 0.92 & 0.97 & 0.91 & 0.98 & 1.00 \\
\hline
\end{tabular}

Table 6: Correlation matrix of the different material quality responses. 


\subsection{Modelling of tangential grinding force - first processing map}

The constitutive equation of the full model was given in Eq. (4). The different coefficients used to model the tangential grinding force as the response $y$ are given in Table 7. One quick and easy method to compare the importance of each coefficient is to calculate the relative effects $(R E) a_{i} / a_{0}$. This ratio illustrates the importance of each coefficient $\left(a_{i}\right)$ in relation to the constant effect $\left(a_{0}\right)$. In Table 7 , the relative effects $(R E)$ are given in brackets.

\begin{tabular}{|c|c|c|c|c|c|}
\hline \multicolumn{2}{|r|}{ Main effect coefficients } & \multicolumn{2}{|c|}{ Interaction effect coefficients } & \multicolumn{2}{|c|}{$\begin{array}{l}\text { Quadratic effect } \\
\text { coefficients }\end{array}$} \\
\hline$a_{0}$ & 0.0328 (reference sets at $0 \%)$ & $a_{12}$ & $-0.0300(-91 \%)$ & $a_{11}$ & $0.0179(+55 \%)$ \\
\hline$a_{1}$ & $-0.0393(-120 \%)$ & $a_{13}$ & $-0.0302(-92 \%)$ & $a_{22}$ & $-0.0265(-81 \%)$ \\
\hline$a_{2}$ & $0.0330(+101 \%)$ & $a_{14}$ & $0.0095(+29 \%)$ & $a_{33}$ & $0.0332(+101 \%)$ \\
\hline$a_{3}$ & $0.0409(+125 \%)$ & $a_{15}$ & $-0.0046(-14 \%)$ & & \\
\hline$a_{4}$ & $-0.0166(-51 \%)$ & $a_{23}$ & $0.0285(+87 \%)$ & & \\
\hline \multirow[t]{5}{*}{$a_{5}$} & $0.0036(+11 \%)$ & $a_{24}$ & $-0.0038(-12 \%)$ & & \\
\hline & & $a_{25}$ & $0.0030(+9 \%)$ & & \\
\hline & & $a_{34}$ & $-0.0133(-41 \%)$ & & \\
\hline & & $a_{35}$ & $0.0055(+17 \%)$ & & \\
\hline & & $a_{45}$ & $-0.0209(-64 \%)$ & & \\
\hline
\end{tabular}

Table 7: Coefficients of the quadratic model for the tangential grinding force. The relative effects are given in brackets

Figure 4 represents graphically the $R E$ data in Table 7 . It represents in increasing order the additional normalized contribution to the total effect of each coefficient to the contribution of the constant effect coefficient. In the figure, the abscissa thus represents the constant effect coefficient. A relative effect with a negative value, expressed in percent, indicates a reduction in tangential grinding force and conversely, a positive value indicates increased forces. For example, an increase in the wheel speed (parameter $x_{1}$, with a main effect represented by coefficient $a_{1}$ ) causes, without taking into consideration the interaction effects, a significant reduction in grinding forces; up to 120 percent reduction in full scale. On the other hand, an increase in feed speed (parameter $x_{2}$, with a main effect represented by coefficient $a_{2}$ ) induces higher forces.

From Figure 4, it is seen that the relative effects of the wheel speed $\left(R E a_{1}=-120 \%\right)$, the feed speed $\left(R E a_{2}=+101 \%\right)$ and the vertical feed $\left(R E a_{3}=+125 \%\right)$ have the largest influences on the tangential grinding force. In contrast, the ultrasonic assistance $\left(R E a_{4}=-51 \%\right)$ has a limited impact, whereas the crystallographic orientation $\left(R E a_{5}=+11 \%\right)$ is almost negligible. Interestingly, the interactions between the wheel 
speed and feed speed $\left(R E a_{12}=-91 \%\right)$ and the wheel speed and vertical feed $\left(R E a_{13}=-92 \%\right)$ reduce significantly the tangential force.

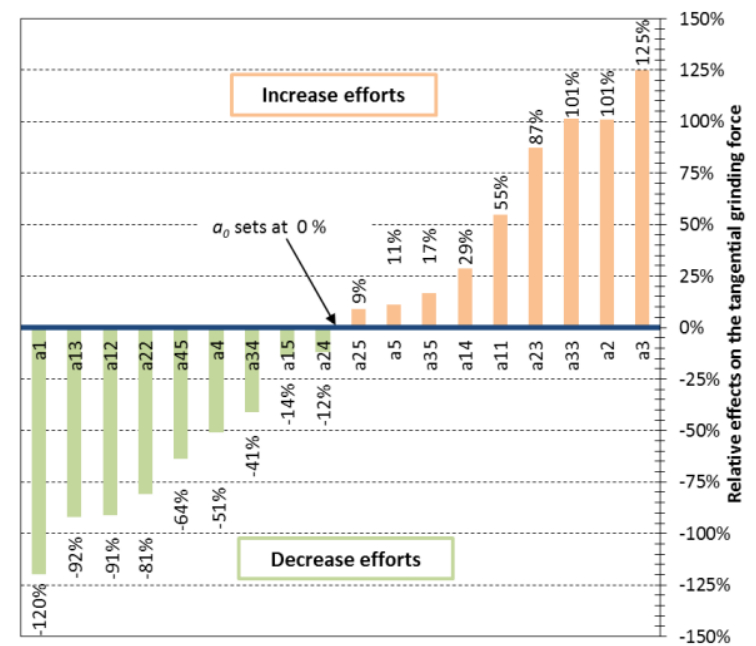

Figure 4: Graphical representation in increasing order of the relative effects on the grinding tangential force.

\subsection{Optimization of model for the tangential grinding force}

For models with four or more variables, simple geometric representations of the dependencies are impossible and this is the case for our results. Consequently, we cannot find by inspection the best set of operational parameters and so, we must use an optimization procedure to determine the optimum. In this work, an interior point method which solves linear and nonlinear convex optimization problems was used. This method constrains the optimization procedure to operate within the boundaries of the process parameter space. This optimization method is an iterative process and 26 iterations were necessary to find the set of parameters yielding the best local optimum.

Table 8 lists the values of the set of parameters, which should significantly reduce the tangential grinding force as compared to the constant effect $a_{0}$ (the value $0 \%$ in Fig. 4). Actually, the set of parameters in Table 8 predicts a decrease of $191 \%$ for the relative amplitude of the measured spindle torque, and hence the tangential grinding force. Because of the weak correlation between tangential and normal grinding forces, we expect that the normal force will follow a similar trend. 


\begin{tabular}{|c|c|c|c|}
\hline \multicolumn{4}{|c|}{ Best local optimum for minimizing the tangential grinding force } \\
\hline $\begin{array}{c}\text { Coded } \\
\text { variables }\end{array}$ & Controlled factor & $\begin{array}{c}\text { Optimum } \\
\text { (Value in coded space) }\end{array}$ & $\begin{array}{c}\text { Optimum } \\
\text { (Value in real space) }\end{array}$ \\
\hline$x_{1}$ & Wheel speed & 0.103 & $\approx 4400 \mathrm{rpm}($ or $17.4 \mathrm{~m} / \mathrm{s})$ \\
\hline$x_{2}$ & Feed speed & -1 & $60 \mathrm{~mm} / \mathrm{min}$ \\
\hline$x_{3}$ & Vertical feed & -0.042 & $\approx 11 \mu \mathrm{m} /$ pass \\
\hline$x_{4}$ & Ultrasonic assistance & +1 & Yes \\
\hline$x_{5}$ & Crystallographic orient. & +1 & $c$-axis \\
\hline
\end{tabular}

A set of parameters that optimizes the tangential grinding force, does not necessarily optimize the productivity of the process. To account for this observation, we have searched for another local optimum in the force model and evaluated how this second set of parameters affects productivity.

The set of parameters presented in Table 9 yields a satisfactory result with respect to productivity: the specific material removal rate $(S M R R)$ is increased by a factor of four as compared to the constant effect for the SMMR. This is discussed in more details in Section 3.7 .

The set of parameters in Table 9, used with the tangential force model, also predicts a reduction in tangential grinding force of $-86 \%$. In this new configuration, the wheel speed is significantly increased, whereas the vertical feed is reduced. Therefore, the second set of parameters is considered as a good compromise to minimize grinding forces and maximize productivity.

\begin{tabular}{|c|c|c|c|}
\hline \multicolumn{2}{|c|}{ Second local optimum in terms of tangential grinding force with improved productivity rate } \\
\hline $\begin{array}{c}\text { Coded } \\
\text { variables }\end{array}$ & Controlled factor & $\begin{array}{c}\text { Optimum } \\
\text { (Value in coded space) }\end{array}$ & $\begin{array}{c}\text { Optimum } \\
\text { (Value in real space) }\end{array}$ \\
\hline$x_{1}$ & Wheel speed & +1 & $7500 \mathrm{rpm}($ or $30 \mathrm{~m} / \mathrm{s})$ \\
\hline$x_{2}$ & Feed speed & +1 & $400 \mathrm{~mm} / \mathrm{min}$ \\
\hline$x_{3}$ & Vertical feed & -0.473 & $\approx 6.7 \mu \mathrm{m} / \mathrm{pass}$ \\
\hline$x_{4}$ & Ultrasonic assistance & +1 & Yes \\
\hline$x_{5}$ & Crystallographic orient. & +1 & $c$-axis \\
\hline
\end{tabular}

Table 9: Second best local optimum set of parameters in terms of tangential grinding force.

\subsection{Modelling of material quality - first processing map}

The same procedure as in Sections 3.2 is applied here, but now for DoE models in terms of material quality, defined by the various responses discussed in Section 2.5, Table 5. The first processing map is established for the median defect area. Other quality parameters will be discussed in Section 3.6.

The resolution method provides 19 new coefficients for the model. They are given in Table 10 and their respective relative effects are given in brackets. 


\begin{tabular}{|c|c|c|c|c|c|}
\hline \multicolumn{2}{|r|}{ Main effect coefficients } & \multicolumn{2}{|c|}{ Interaction effect coefficients } & \multicolumn{2}{|c|}{$\begin{array}{l}\text { Quadratic effect } \\
\text { coefficients }\end{array}$} \\
\hline$a_{0}$ & 1079.26 (reference sets at $0 \%$ ) & $a_{12}$ & $215.64(+20 \%)$ & $a_{11}$ & $-728.97(-68 \%)$ \\
\hline$a_{1}$ & $-153.71(-14 \%)$ & $a_{13}$ & $-184.92(-17 \%)$ & $a_{22}$ & $-186.32(-17 \%)$ \\
\hline$a_{2}$ & $154.19(+14 \%)$ & $a_{14}$ & $64.91(+6 \%)$ & $a_{33}$ & $776.44(+72 \%)$ \\
\hline$a_{3}$ & $40.43(+4 \%)$ & $a_{15}$ & $-291.04(-27 \%)$ & & \\
\hline$a_{4}$ & $287.62(+27 \%)$ & $a_{23}$ & $-376.59(-35 \%)$ & & \\
\hline \multirow[t]{5}{*}{$a_{5}$} & $-194.18(-18 \%)$ & $a_{24}$ & $143.97(+13 \%)$ & & \\
\hline & & $a_{25}$ & $-216.92(-20 \%)$ & & \\
\hline & & $a_{34}$ & $-32.90(-3 \%)$ & & \\
\hline & & $a_{35}$ & $64.56(+6 \%)$ & & \\
\hline & & $a_{45}$ & $33.74(+3 \%)$ & & \\
\hline
\end{tabular}

Table 10: Coefficients of the quadratic model for the median defect area. The relative effects are given in brackets

Figure 5 shows the relative effects sorted out in increasing order. As for Fig. 4 presenting the tangential grinding force, this graphical representation allows an easy visualization of the importance of each parameter and the influence of their different interactions.

Note that the quadratic effects $\left(a_{11}\right.$ and $\left.a_{33}\right)$ are the most significant ones, which indicates that a linear model would not be appropriate because of a strong curvature of the surfaces in our parameter space. Also, the influence of the grinding direction $x_{5}$ ( $c$ - and $m$ directions) has limited influence on the grinding process.

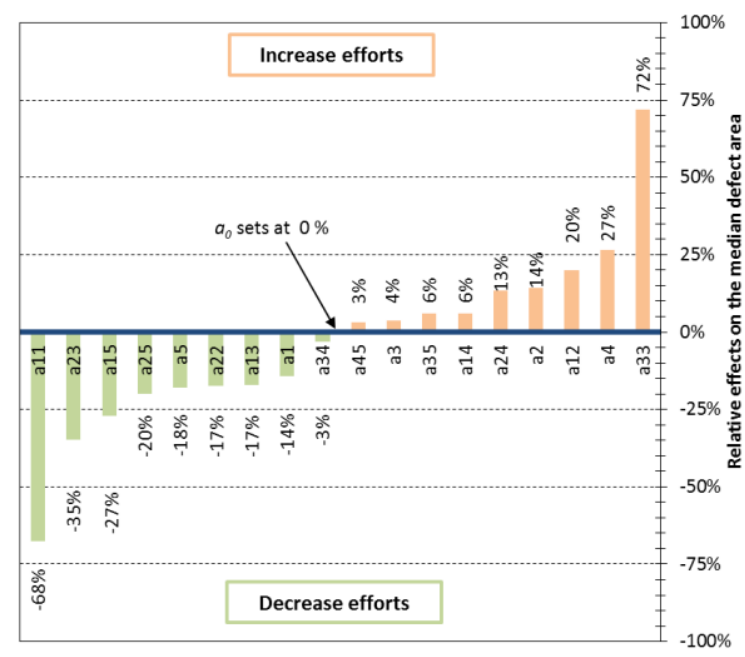

Figure 5: Graphical representation in increasing order of the relative effects on the median defect area. 
When developing models, the parameters with little effects are often disregarded and a new model is developed with the remaining coefficients. The main objective is to reduce the complexity of the model. Figure 5 shows that three coefficients have a relative effect below $5 \%\left(a_{34}=-3 \%, a_{45}=3 \%\right.$ and $\left.a_{3}=4 \%\right)$, so that they can be practically neglected. The question then arises whether or not to neglect a main factor with little direct effect, if it has a nonnegligible interaction, as for instance the case for the vertical feed $\left(x_{3}\right)$. In the present case, even though all coefficients are kept for the later development of the model, presently disregarding these three effects brings valuable information to check the statistical validity of the model. Indeed, it is possible to eliminate coefficients $x_{3}, x_{34}$ and $x_{45}$ and "lump" their effects in the residual errors. Under such circumstances, the number of degrees of freedom of the model increases and an analysis of variance on the data (ANOVA) can be carried out to obtain the probability of an effect being significant or not. In this particular case, all effects are found to be significant as their probability to be random is less than $3 \%$. This observation gives confidence in the model and its results!

\subsection{Optimization of material quality using the model of the defect area}

Keeping the full model based on Eq. (4), we apply the same optimization procedure as for the grinding force in Section 3.3 to obtain the set of parameters resulting in the best achievable material quality characterized by the median defect area. The optimization algorithm is run under constraints with the set of coefficients given in Table 10. The best local optimum is obtained after 9 iterations and the set of parameters is given in Table 11. With this set of parameters, the model predicts that the median defect area significantly decreases (by 184\%) as compared to the value associated with the constant effect $a_{0}$.

A second local optimum is found and the corresponding set of parameters is given in Table 12. With this solution, a decrease of $138 \%$ in relative value is expected as compared to the constant effect contribution. This set of parameters gives a worse productivity rate than the best local optimum defined in Table 11 since the feed speed $\left(x_{2}\right)$ and the vertical feed $\left(x_{3}\right)$ both have lower values. In addition, the optimum defined in Table 12 requires the use of USA to compensate for the $30 \%$ reduction in depth of cut as compared to the value for the first local optimum (from 13.5 to $\approx 9.5 \mu \mathrm{m} /$ pass). 


\begin{tabular}{|c|c|c|c|}
\hline \multicolumn{4}{|c|}{ Best local optimum in terms of median defect area } \\
\hline $\begin{array}{c}\text { Coded } \\
\text { variables }\end{array}$ & Controlled factor & $\begin{array}{c}\text { Optimum } \\
\text { (Value in coded space) }\end{array}$ & $\begin{array}{c}\text { Optimum } \\
\text { (Value in real space) }\end{array}$ \\
\hline$x_{1}$ & Wheel speed & +1 & $7500 \mathrm{rpm}($ or $30 \mathrm{~m} / \mathrm{s})$ \\
\hline$x_{2}$ & Feed speed & +1 & $400 \mathrm{~mm} / \mathrm{min}$ \\
\hline$x_{3}$ & Vertical feed & 0.273 & $13.5 \mu \mathrm{m} / \mathrm{pass}$ \\
\hline$x_{4}$ & Ultrasonic assistance & -1 & No \\
\hline$x_{5}$ & Crystallographic orient. & +1 & $c$-axis \\
\hline
\end{tabular}

Table 11: Set of parameters for the first (and best) local optimum of the median defect area.

\begin{tabular}{|c|c|c|c|}
\hline \multicolumn{4}{|c|}{ Second local optimum in terms of median defect area } \\
\hline $\begin{array}{c}\text { Coded } \\
\text { variables }\end{array}$ & Controlled factor & $\begin{array}{c}\text { Optimum } \\
\text { (Value in coded space) }\end{array}$ & $\begin{array}{c}\text { Optimum } \\
\text { (Value in real space) }\end{array}$ \\
\hline$x_{1}$ & Wheel speed & +1 & $7500 \mathrm{rpm}($ or $30 \mathrm{~m} / \mathrm{s})$ \\
\hline$x_{2}$ & Feed speed & -1 & $60 \mathrm{~mm} / \mathrm{min}$ \\
\hline$x_{3}$ & Vertical feed & -0.166 & $\approx 9.5 \mu \mathrm{m} / \mathrm{pass}$ \\
\hline$x_{4}$ & Ultrasonic assistance & +1 & Yes \\
\hline$x_{5}$ & Crystallographic orient. & +1 & -axis \\
\hline
\end{tabular}

Table 12: Set of parameters for the second local optimum of the median defect area.

\subsection{Search for the best optimum and validation tests with respect to material quality}

In the previous sections, models for the grinding force and the median defect area have been developed and optimized. The parameters defining the best and second best optima for each optimized characteristic are given in Tables 8, 9, 11 and 12, respectively. Inspection of these tables shows that none of the four optimal conditions overlaps indicating that a compromise is necessary to meet objectives of high groove quality and low grinding forces simultaneously. A comparison of the data in the four tables reveals that the second local optimum in terms of grinding forces (Table 9) corresponds fairly well with the best local optimum for the median defects area (Table 11). In both set of parameters, the wheel speed, the feed speed and crystallographic orientation are identical. By contrast, the vertical feed (or the depth of cut) is more or less twice lower for the optimum in terms of forces. Moreover, ultrasonic assistance has a pronounced effect on reducing forces, while it does not improve the median defect area and therefore the grinding quality. Finally, we observe that the best optimum for the median defect area also offers the best compromise between reduction of forces and productivity. Therefore, by inspection of the results, we can conclude that the set of parameters of Table 11 provides the best compromise in achieving grinding quality and productivity.

To validate this model and its interpretation, a series of additional experiments were carried out with the optimal set of parameters given in Table 11. This validation is of utmost importance when modeling using statistical methods such as design of experiment. 
The validation tests were performed on both Verneuil and Kyropoulos materials in the hope of determining possible differences between these two sapphire types. To check again the reproducibility of the tests, seven experiments (3 with Verneuil and 4 with Kyropoulos) were conducted with the set of optimal parameters in Table 11.

The results of the validation experiments are plotted in Fig. 6 together, for comparison, with all previous results of the DoE experimental plan. This graph shows the measured values of the median defect area plotted as a function of the parameter run number. The runs are ranked on the horizontal axis ( $x$-axis) from the best to the worst result (from left to right). Each test, has received an identification number called "Groove ID ". For clearer graphic representation and easier comparison, the runs were ranked only one time for the median defects area and this order is kept for all future comparisons. For example, ID 20 refers to the same test in all graphs from Fig. 6 on. The tests have the following ID numbers:

- ID 1 to 3 correspond to the optimal runs on Verneuil;

- ID 4 to 7 correspond to the optimal runs on Kyropoulos;

- ID 8 to 55 correspond to all the previous runs of the DoE plan.

Figure 6 shows that little differences are seen between the additional tests (ID 1 to ID 7 ), with the set of parameters for the first (and best) local optimum of the median defect area (set of parameters of Table 11), and the best results obtained from the DoE plan (ID 8 to ID 15). This validates the optimized model. In addition, the spread in the results for the optimal experimental runs in Fig. 6 is relatively small, indicating a good reproducibility of the tests. This is particularly true when considering that each experiment was performed on the same batch of sapphire but on different samples of sapphire, at various times and with some variation of environmental conditions (room temperature and relative humidity). On the basis of the data in Fig. 6, we conclude that no significant differences between Verneuil and Kyropoulos sapphires can be observed. Although the data are not presented here for the sake of brevity, we draw the same conclusion when considering grinding forces. 


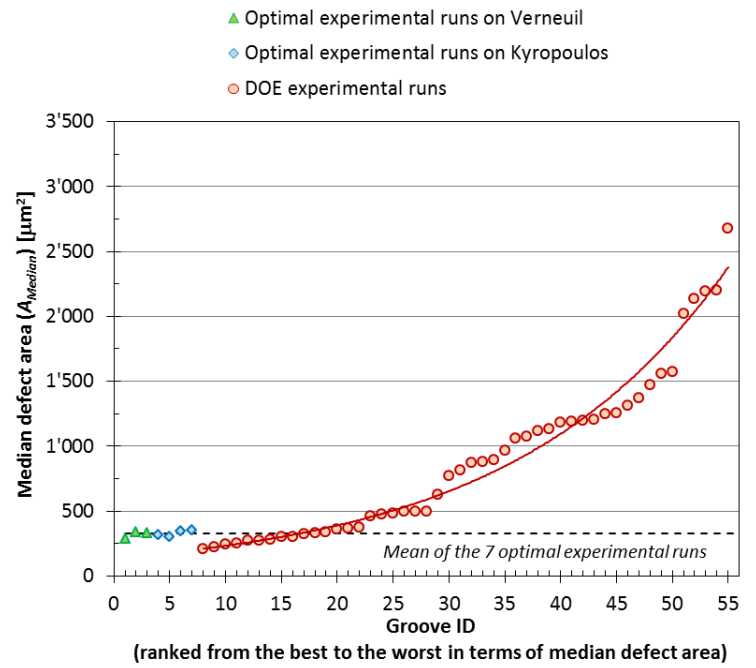

Figure 6: Validation of the optimal set of parameters for the criterion of median defects area.

In Table 6, the median defect area and the median defect height have a coefficient of correlation of 0.90 . Consequently, we expect that the model developed for the median defect area is also valid for the median defect height. To confirm this hypothesis and thereby enhance the confidence in the model, all results are plotted in Fig. 7 in terms of median defect height, in a manner similar to what was done for the median defect area in Fig. 6. From Figure 7, it is evident that, for the tests ranked between 1 and 25, the results are consistent with the model predictions. The additional tests still appear to be optimal in comparison with all the DoE tests and this validates the model based on the set of parameters of Table 11. As we noticed for the median defect area, the minimum median defect height has a limited minimum value (more or less $10 \mu \mathrm{m}$ ). Although not shown here, a similar trend is observed for the minimum defect height with a limit value of $1 \mu \mathrm{m}$. This result is consistent with the investigation of sapphire cracking behavior during nanoindentation using different indenter shape (Graça, 2016). 


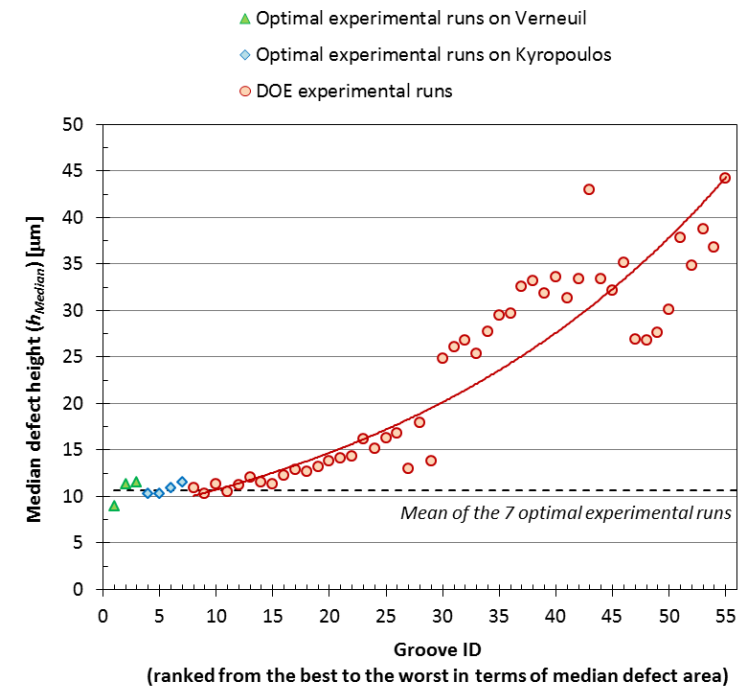

Figure 7: Validation of the optimal set of parameters for the criterion of median defect height.

\subsection{Verification of the optimum with respect to productivity}

In Section 3.6, we validated the models for material quality and for grinding forces. Although these process parameters are important to meet geometric and dimensional specifications for the ground grooves, a minimum level of productivity is required for the "optimized process" to be industrially viable. As mentioned in Section 2.4, we express productivity in terms of the specific material removal rate $Q_{w}^{\prime}(S M R R)$ and the total processing time.

The $S M R R$ was defined in Eq. (2) in Section 2.4. In our case, the feed speed $v_{a}=x_{2}$ and the depth of cut $a_{e}$ corresponds to the vertical feed $\left(x_{3}\right)$, so that Eq. (2) can be rewritten as:

$$
Q_{w}^{\prime}=v_{a} \cdot a_{e}=x_{2} \cdot x_{3}
$$

Applying the procedure used for the previous section, we plot in Fig. 8 the results $Q_{w}^{\prime}$ calculated with Eq. (5) versus "Groove ID". From this figure, it is seen that the optimum parameters determined in the preceding section (Table 11) provide the second highest $Q_{w}^{\prime}$ values. Further increasing $Q_{w}^{\prime}$ to its highest-value would have a very negative impact on the process quality, because the best experiment with the highest $Q_{w}^{\prime}$-value is only ranked $25^{\text {th }}$ with respect to process quality, with $A_{\text {Median }}$ and $h_{\text {Median }}$ values of approximately 500 $\mu \mathrm{m}^{2}$ and $16.5 \mu \mathrm{m}$, respectively. 
Total processing time represents another important metric of industrial productivity. In this study, the calculation of the processing time takes into account the actual time spent machining, but also the time for taking the surface reference as well as the approach and return time between passes. Figure 9, which plots processing time versus "Groove ID" indicates that the selected optimum has the second best value in terms of total processing time. With 323 seconds (or $5 \mathrm{~min}$ and $23 \mathrm{sec}$ ), it is relatively close to the fastest configuration of the DoE plan (240 seconds or $4 \mathrm{~min}$ ). As for increasing $Q_{w}^{\prime}$ to its highest achievable value, decreasing the total processing time to its lowest achievable value would have a very negative impact on the process quality.

Considering the results in Figs 8 and 9, we can conclude that the optimized model in Table 11 has been validated, not only in terms of grinding forces and material quality, but also in terms of productivity.

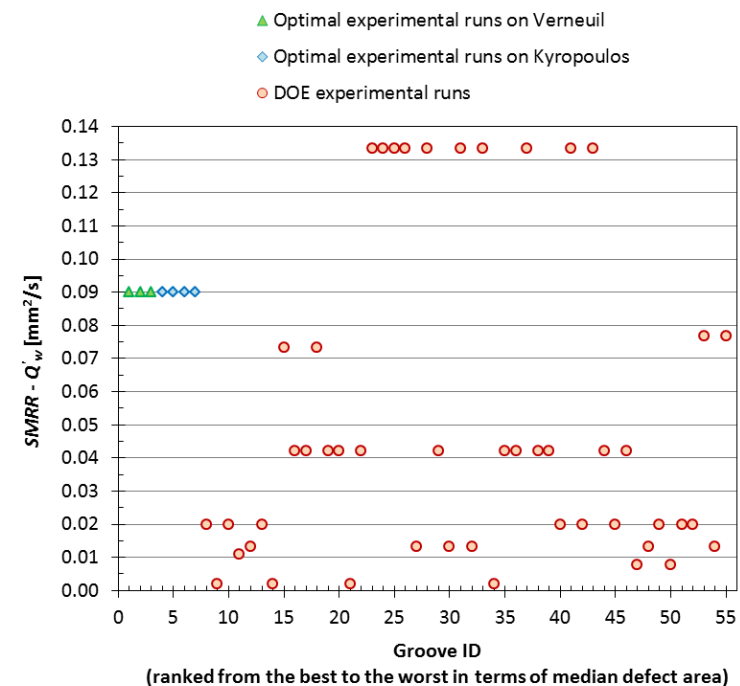

Figure 8: Verification of the effect of the optimal set of parameters on productivity characterized by $S M R R$ 


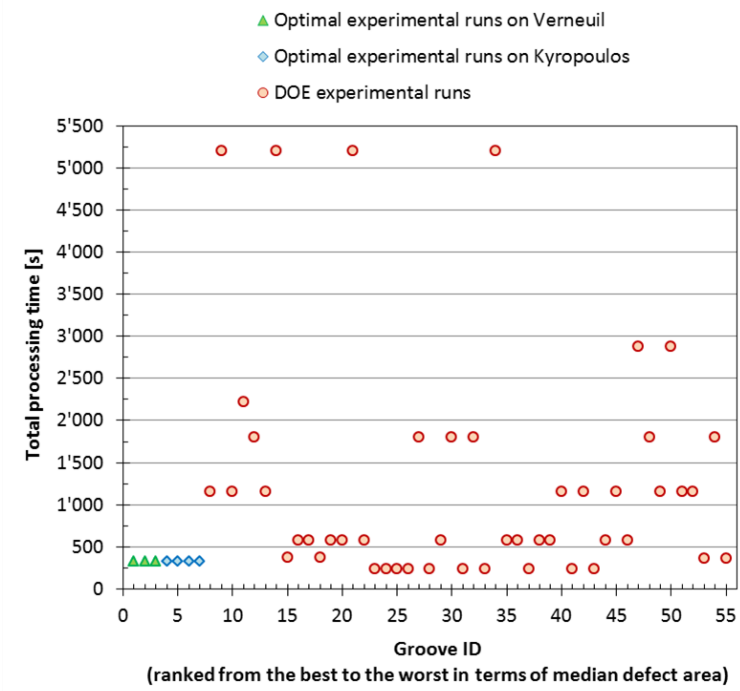

Figure 9: Verification of the effect of the optimal set of parameters on productivity characterized by total processing time.

\section{DISCUSSIONS}

\subsection{Discussion of grinding force model (Section 3.2)}

In Figure 4, it was seen that the relative effects of the wheel speed $\left(R E_{a 1}=-120 \%\right)$, the feed speed $\left(R E_{a 2}=+101 \%\right)$ and the vertical feed $\left(R E_{a 3}=+125 \%\right)$ have the largest influences on the tangential grinding force. These experimental results are consistent with experimental results in the literature (Polini and Turchetta, 2004) and more details about the details on the geometrical considerations can be found in Kurrein (1927), Peters (1966) and Polini and Turchetta (2004). Actually, the trends observed in this work may be explained by expressing the resultant global grinding force $R$ in terms of two sets of different components:

- the tangential $\left(F_{c}\right)$ and radial $\left(F_{r}\right)$ grinding forces with respect to the grinding wheel calculated from the sum of the forces acting on each individual grain. These forces are given in the first part of Eq. (6) (Polini and Turchetta, 2004).

- the directly measured equivalent tangential $\left(F_{t}\right)$ and normal $\left(F_{n}\right)$ grinding forces with respect to work piece. These forces are given in the second part of Eq. (6) via the resultant $R$ (Polini and Turchetta, 2004).

$$
\begin{aligned}
& F_{c}=K_{c} \cdot h_{e q}^{v_{c}}=R \cdot \sin \delta \\
& F_{r}=K_{r} \cdot h_{e q}^{v_{r}}=R \cdot \cos \delta
\end{aligned}
$$


In the first part of Eq. (6), $K_{c}$ and $K_{r}$ correspond to the grinding force coefficients, $v_{c}$ and $v_{r}$ are some constants and $h_{e q}$ is the equivalent chip thickness, which is is defined by (Kurrein, 1927; Peters, 1966; Polini and Turchetta, 2004):

$$
h_{e q}=\frac{x_{2} \cdot a_{e}}{x_{1}}=\frac{x_{2} \cdot x_{3}}{x_{1}}
$$

where $x_{1}$ and $x_{2}$ are the wheel speed and the feed speed, respectively, and $a_{e}$ is the depth of cut. In this work, it is possible to assume that the depth of cut is equal to the vertical feed so that $a_{e}=x_{3}$.

The second part of Eq. (6) considers the grinding forces acting on the workpiece along the feed speed direction and along the perpendicular to the feed speed direction via the resultant $R$ where $R=\sqrt{F_{t}^{2}+F_{n}^{2}}$ and $\delta$ is the angle between $F_{r}$ and $R$ (See Fig. 3 in (Polini and Turchetta, 2004)).

Further, on the basis of experimental observations, we assume in first approximation that $F_{n}$ is proportional to $F_{t}$ (i.e. $F_{n} / F_{t}=\alpha$ ). Integrating Eq. (7) into Eq. (6) and replacing $R$ using $F_{n} / F_{t}=\alpha$ in Eq. (6), $F_{c}$ and $F_{r}$ become:

$$
\begin{aligned}
& F_{c}=K_{c} \cdot\left(\frac{x_{2} \cdot x_{3}}{x_{1}}\right)^{v_{c}}=\sqrt{F_{t}^{2}+\left(\alpha F_{t}\right)^{2}} \cdot \sin \delta=F_{t} \sqrt{1+\alpha^{2}} \sin \delta \\
& F_{r}=K_{r} \cdot\left(\frac{x_{2} \cdot x_{3}}{x_{1}}\right)^{v_{r}}=\sqrt{\left(\frac{F_{n}}{\alpha}\right)^{2}+F_{n}^{2}} \cdot \cos \delta=F_{n} \sqrt{\frac{1}{\alpha^{2}}+1} \cos \delta
\end{aligned}
$$

As the grinding wheel was always of the same type for all runs, $K_{c}$ can be assumed to be constant in Eq. (8a) for the tangential grinding force. Consequently, from Eq. (8a), it is obvious that increasing the feed speed $\left(x_{2}\right)$ and/or the vertical feed $\left(x_{3}\right)$ increases the tangential $\left(F_{c}\right)$ grinding force but also the measured tangential force $F_{t}$. Following the same reasoning for the radial grinding force, increasing the feed speed $\left(x_{2}\right)$ and/or the vertical feed $\left(x_{3}\right)$ increases the radial $\left(F_{r}\right)$ grinding force but also the measured normal force $F_{n}$. In contrast, an increase of the wheel speed $\left(x_{l}\right)$ decreases $F_{c}$ and $F_{r}$ but also $F_{t}$ and $F_{n}$. 


\subsection{Discussion of material quality model (Section 3.4)}

In Section 4.1, Eq. (8) established the correlation between the grinding parameters $\left(x_{1}\right.$, $x_{2}$, and $\left.x_{3}\right)$ and the grinding forces $\left(F_{t}\right.$ and $\left.F_{n}\right)$. We also mentioned based on experimental evidence, that, in first approximation, the ratio between the normal and the tangential forces can be assumed constant, i.e. $F_{n} / F_{t} \approx \alpha$. Furthermore, in Table 6 , the correlation between the median defect area $\left(A_{\text {Median }}\right)$ and the median defect height $\left(h_{\text {Median }}\right)$ is 0.9 . Consequently, all results pertaining to grinding forces versus material quality can be inferred from the relation between the measured normal force $\left(F_{n}\right)$ and the median defect height $\left(h_{\text {Median }}\right)$, which only needs being considered.

On the basis of fracture mechanics and indentation mechanics analysis and experimental results (Lawn, 1997; Malkin and Hwang, 1996; Marshall et al., 1982; Raju and Newman, 1979; Suratwala et al., 2006; Wasmer et al., 2008a; Wasmer et al., 2008b; Wasmer et al., 2013), one can plausibly argue that the lateral crack will tend to initiate at the depth of cut $a_{e}$ (where the stress concentration at the groove corner and the loading are highest) and propagates parallel to the surface. In this work, regardless of the grinding direction ( $m$ - or $c$-axis), the cracking plane is always the same; the $a$-plane. In addition, this plane is known to have a significantly lower fracture toughness $\left(K_{I c}\right)$ value compared to the toughness for the $c$ - and $m$-planes. It is also close to the weakest $R$-plane (Graça et al., 2014). Thus, it can be concluded that lateral cracks, and chipping, are favored to grow along the $a$-plane. In contrast, the grinding direction with respect to the crystallographic axes (along the $m$ - or $c$-axis) does not significantly influence the cracking and chipping behavior during grinding This observation is consistent with Fig. 5 where the coefficient $a_{5}$ of main effect $x_{5}$ has a low impact on the median defect area $\left(R E a_{5}=-18 \%\right)$.

\subsection{Discussion of the search for the best optimum and validation tests with respect to} material quality (Section 3.6)

Figure 6 indicates that our grinding process cannot be optimized to produce median defect areas smaller than $320 \mu \mathrm{m}^{2}$ whereas the smallest defect area measured was as low as $25 \mu^{2}$. In turn, this observation suggests that grinding of sapphire occurs by the formation of brittle chips of a minimum area limited by the size of the interacting nucleated radial and lateral cracks underneath the diamond grains of the wheel. This interpretation is consistent with findings in the literature (Polini and Turchetta, 2004; Wasmer et al., 2008a; Wasmer et al., 2008b). Polini and Turchetta (2004), working with rock, showed that the 
specific grinding energy $E_{c}$ increases non-linearly as the equivalent chip thickness $h_{e q}$ decreases and that $E_{c}$ tends to infinity when $h_{e q}$ reaches $0.2 \mu \mathrm{m}$, thus making the generation of smaller chips impossible. Moreover, Wasmer et al. (2008a; 2008b) demonstrated that during scratching of gallium arsenide, the minimum length of the nucleated cracks is limited to a lower bound, which depends on the tool contact geometry. The lower bound arises because the local conditions for the nucleation of a crack require a more or less fixed amount of strain energy build up in the contact region of a tool (or diamond grain). Once the crack is nucleated, the stored energy is released and dissipated in part by propagating the crack. The final length of the propagated crack then depends on the amount of stored strain energy at the instant of crack nucleation, which, as mentioned above is more or less a constant and hence causes the limitation on the final crack length.

\section{CONCLUSIONS}

Grinding experiments of sapphire have been reported. The effect of the wheel speed, the feed speed, the vertical feed, the ultrasonic assistance (USA) and the crystallographic orientation ( $c$ - and $m$-directions) has been investigated. The experiments were planned based on a two-level fractional factorial design to be able to develop a quadratic model. The responses were used to develop models for grinding forces, grinding quality and productivity.

It is found that the tangential forces decrease with either an increase of the wheel speed $\left(x_{1}\right)$ or a decrease of the feed speed $\left(x_{2}\right)$ and/or the vertical feed $\left(x_{3}\right)$. An optimization procedure shows that the best local optimum in terms of forces is achieved with a wheel speed of $16 \mathrm{~m} / \mathrm{s}$, a feed speed of $60 \mathrm{~mm} / \mathrm{min}$, a vertical feed of approximately $11 \mu \mathrm{m} /$ pass with the ultrasonic assistance and along the $c$-direction. A second best optimum, taking into consideration the productivity, is obtained with a wheel speed of $30 \mathrm{~m} / \mathrm{s}$, a feed speed of $400 \mathrm{~mm} / \mathrm{min}$, a vertical feed of $6.7 \mu \mathrm{m} /$ pass with the ultrasonic assistance and along the $c$-direction.

When considering the grinding quality, it is observed that the quadratic effects of the main parameters (wheel speed $\left(x_{1}\right)$ and vertical feed $\left(x_{3}\right)$ ) are the most important ones. The best local optimum has been obtained with a wheel speed of $30 \mathrm{~m} / \mathrm{s}$, a feed speed of 400 $\mathrm{mm} / \mathrm{min}$, a vertical feed of approximately $13.5 \mu \mathrm{m} /$ pass with no ultrasonic assistance and along the $c$-direction. This optimum is also very close to the optimum for material removal 
rate per unit active grinding wheel width $\left(Q_{w}^{\prime}\right)$ or productivity. Although grinding along the $c$-direction is predicted by the models to reduce the wheel forces and increase the productivity, it is demonstrated that the grinding direction, actually, plays a minor role. This is due to the fact that the defect height and/or area are related to the lateral cracks and that in all cases, the lateral cracks propagate along the weak $a$-plane. It is also seen that, by and large, the smallest defect height and median defect height are around 1 and $10 \mu \mathrm{m}$, respectively, which is consistent with the literature (Graça, 2016).

Although USA is known to reduce sub-surface damages in ceramics (Qu et al., 2000), this may not always be the case. This is particularly true when considering the height and/or the area of the defects at the surface edges of the groove, as it is the case in this study. Under such circumstances, we note that USA helps reducing the grinding forces and improving productivity, but have a rather deleterious effect on the groove quality.

Finally, the optimum process parameters in Table 11 have been used for performing additional experiments and validate the model. These additional experiments have pointed out that little differences exist between Verneuil and Kyropulos sapphire. The results have confirmed the validity of the model not only for the median defect area but also for the median defect height. The model proposed correlates very well with material removal rate and productivity and it is certainly applicable to other brittle materials such as ceramics.

The approach presented here, although somewhat complex, can be advantageously applied to other grinding configurations and processes.

\section{Acknowledgments}

Part of this work was supported by the Swiss Confederation's Innovation Promotion Agency (CTI), project number 10610.2 PFIW-IW. The authors would like to thank Dr Jean-Marie Fürbringer for the fruitful discussion about the DoE plan, Hrand Djevahirdjian S.A. for the production and orientation of the samples and Stettler Sapphire S.A. for the sample polishing. 


\section{REFERENCES}

Agarwal, S., Rao, P.V., 2010. Modelling and prediction of surface roughness in ceramic grinding. Int. J. Mach. Tools Manuf. 50, 1065-1076, doi:10.1016/j.ijmachtools.2010.08.009.

Ahn, Y., Farris, T.N., Chandrasekar, S., 1998. Sliding microindentation fracture of brittle materials: Role of elastic stress fields. Mech. Mater. 29, 143-152, doi:10.1016/S01676636(98)00012-X.

Box, G.E.P., Hunter, W.J., Hunter, J., 1978. Statistics for Experimenters, An introduction to design, data analysis and model building. Wiley Series in Probability and Mathematical Statistics, John Wyley and Son, NY.

Brehl, D.E., Dow, T.A., 2008. Review of vibration-assisted machining. Prec. Eng. 32, $153-$ 172, doi:10.1016/j.precisioneng.2007.08.003.

Brinksmeier, E., Aurich, J.C., Govekar, E., Heinzel, C., Hoffmeister, H.-W., Klocke, F., Peters, J., Rentsch, R., Stephenson, D.J., Uhlmann, E., Weinert, K., Wittmann, M., 2006. Advances in modeling and simulation of grinding processes. Keynote Paper, Ann. CIRP Manuf. Technol. 55, 667-696, doi:10.1016/j.cirp.2006.10.003.

Evans, A.G., Marshall, D.B., 1981. Wear mechanisms in ceramics in Fundamentals of friction and wear of materials, Ed. by Rigney, ASME , 439-452.

Funkenbusch, P.D., Zhou, Y., Takahashi, T., Golini, D., 1998. Grinding of single crystal sapphire: workpiece roughness correlations. Wear 218, 1-7, doi:10.1016/S00431648(98)00206-3.

Graça, S., Trabadelo, V., Neels, A., Kuebler, J., Le Nader, V., Gamez, G., Döbeli, M., Wasmer, K., 2014. Influence of mosaicity on the fracture behavior of sapphire. Acta Mat. 67, 67-80, doi:10.1016/j.actamat.2013.12.004.

Graça, S., 2016. Private communication.

Groover, M.P., 2010. Fundamentals of modern manufacturing: materials, processes and systems. fourth ed., John Wiley \& Sons Inc.

Inasaki, I., 1987. Grinding of hard and brittle materials, Keynote Paper, Ann. CIRP Manuf. Technol. 36, 463-471, doi:10.1016/S0007-8506(07)60748-3.

Inkson, B.J., 2000. Dislocations and twinning activated by the abrasion of $\mathrm{Al}_{2} \mathrm{O}_{3}$. Acta Mater. 48, 1883-1895, doi:10.1016/S1359-6454(99)00468-1. 
Kim, H., Matsumaru, K., Takata, A., Ishizaki, K., 2003. Grinding behaviour of silicon wafer and sintered $\mathrm{Al}_{2} \mathrm{O}_{3}$ by constant force feeding grinding system. Adv. Technol. Mat. Mat. Proc. J. 5, 50-53.

Kurrein, M., 1927. Die Bearbeitbarket der Metalle in Zusammenhang mit der Festigkeitsprüfung. Werkstattechnik 21, 612-621.

Lawn, B.R., Evans, A.G. Marshall, D.B., 1980. Elastic/plastic indentation damage in ceramics: the median/radial crack system. J. Amer. Ceram. Soc. 63, 574-581 doi:10.1111/j.1151-2916.1980.tb10768.X.

Lawn, B., 1997. Fracture of Brittle Solids, second ed., Cambridge University Press.

Malkin, S., 1989. Grinding Technology: Theory and applications of machining with abrasives. Ellis, Horwood Limited.

Malkin, S., Hwang, T.W., 1996. Grinding mechanisms for ceramics. Keynote Paper, Ann. CIRP Manuf. Technol. 45, 569-580, doi:10.1016/S0007-8506(07)60511-3.

Marshall, D.B., Lawn, B.R., Evans, A.G., 1982. Elastic/plastic indentation damage in ceramics: the lateral crack system. J. Amer. Ceram. Soc. 65, 561-566, doi:10.1111/j.11512916.1982.tb10782.X.

Marinescu, I.D., Tonshöff, H.K., Inasaki, I., 2000. Handbook of ceramic grinding and polishing. Noyes publications/William Andrew Publishing LLC, New York.

Mayer, J.E., Fang, G.P., 1995. Effect of grinding parameters on surface finish of ground ceramics. Ann. CIRP Manuf. Technol. 44, 279-282, doi:10.1016/S0007-8506(07)62325-7.

Montgomery, D.C., 2009. Design and analysis of experiments, John Wiley \& Sons Inc.

Pei, Z.J., Prabhakar, D., Ferreira, P.M., 1995. A mechanistic approach to the prediction of material removal rates in rotary ultrasonic machining. J. Eng. Ind. 117, 142-151, doi:10.1115/1.2803288.

Peters, J.M., 1966. Les recherches actuelles dans le domaine de la rectification. Ann. CIRP 15, 21-33.

Polini W., Turchetta, S., 2004. Force and specific energy in stone cutting by diamond mill. Int. J. Mach. Tools Manuf. 44, 1189-1196, doi:10.1016/j.ijmachtools.2004.04.001.

Preston, F.W., 1927. The theory and design of plate glass polishing machines. J. Soc. Glass Technol. 11, 214-256.

Qu, W., Wang, K., Miller, M.H., Huang, Y., Chandra, A., 2000. Using vibration-assisted grinding to reduce subsurface damage. Prec. Eng. 24, 329-337, doi:10.1016/S01416359(00)00043-X. 
Raju, I.S., Newman, J.C., 1979. Stress-intensity factors for a wide range of semi-elliptical surface cracks in finite-thickness plates. Eng. Fract. Mech. 11, 817-829, doi:10.1016/00137944(79)90139-5.

Stepien, P., 2009. A probabilistic model of the grinding process. Appl. Math. Model 33, 3863-3884, doi:10.1016/j.apm.2009.01.005.

Suratwala, T.I., Wong, L.L., Miller, P.E., Feit, M.D., Menapace, J.A., Steele, R.A., Davis, P.A., Walmer, D., 2006. Sub-surface mechanical damage distributions during grinding of fused silica. J. Non-Cryst. Sol. 352, 5601-5617, doi:10.1016/j.jnoncrysol.2006.09.012.

Tönshoff, H.K., Peters, J.M., Inasaki, I., Paul, T., 1992. Modelling and simulation of grinding processes. Keynote Paper, Ann. CIRP Manuf. Technol. 41, 677-688, doi:10.1016/S0007-8506(07)63254-5.

Uhlmann, E., Spur, G., 1998. Surface formation in creep feed grinding of advanced ceramics with and without ultrasonic assistance. Ann. CIRP Manuf. Technol. 47, 249-252, doi:10.1016/S0007-8506(07)62828-5.

Unser, M., Pelle, G., Brun, P., Eden, M., 1989, Automated extraction of serial myocardial borders from M-mode echocardiograms, IEEE T. Med. Imaging. 8, 96-103, Downloadable at http://bigwww.epfl.ch/publications/unser8905.html.

Wasmer, K., Ballif, C., Gassilloud, R., Pouvreau, C., Rabe, R., Michler, J., Breguet, J.M., Solletti, J.-M., Karimi, A., Schulz., D., 2005. Cleavage fracture of brittle semiconductors for the nanometer to the centimeter scale. Adv. Eng. Mat. 7, 309-317, doi:10.1002/adem.200500044.

Wasmer, K., Ballif, C., Pouvreau, C., Schulz, D., Michler, J., 2008a. Dicing of galliumarsenide high performance laser diodes for industrial applications, part I: scratching operation. J. Mater. Process. Tech. 198, 114-121, doi:10.1016/j.jmatprotec.2007.06.055.

Wasmer, K., Ballif, C., Pouvreau, C., Schulz, D., Michler, J., 2008b. Dicing of galliumarsenide high performance laser diodes for industrial applications, part II: cleavage operation. J. Mater. Process. Tech. 198, 105-113, doi:10.1016/j.jmatprotec.2007.06.054.

Wasmer, K., Parlinska-Wojtan, M., Graça, S., Michler, J., 2013. Sequence of deformation and cracking behaviours of gallium-arsenide during nano-scratching. Mater. Chem. Phys. 138, 38-48, doi:10.1016/j.matchemphys.2012.10.033.

Wen, D.H., Wan, Y.H., Hong, T., 2008. Surface integrity induced by abrasive machining sapphire wafer. Adv. Mat. Res. 53-54, 311-316, 10.4028/www.scientific.net/AMR.5354.311 . 


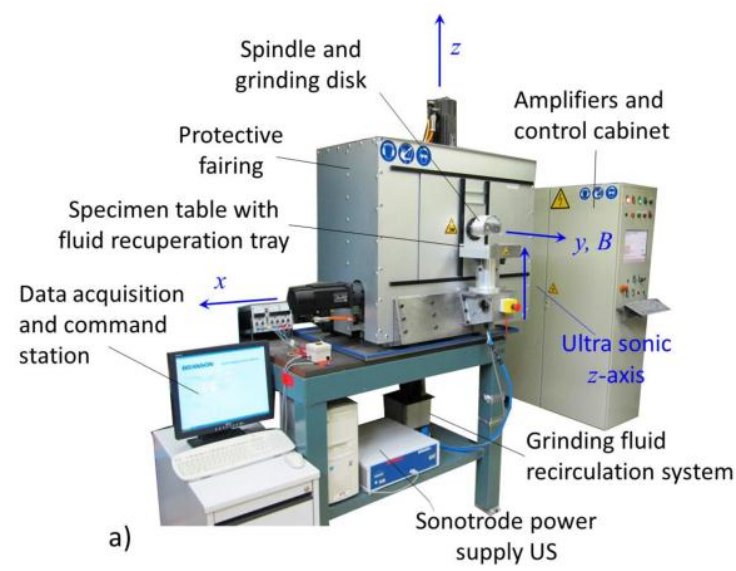

Experimental set-up
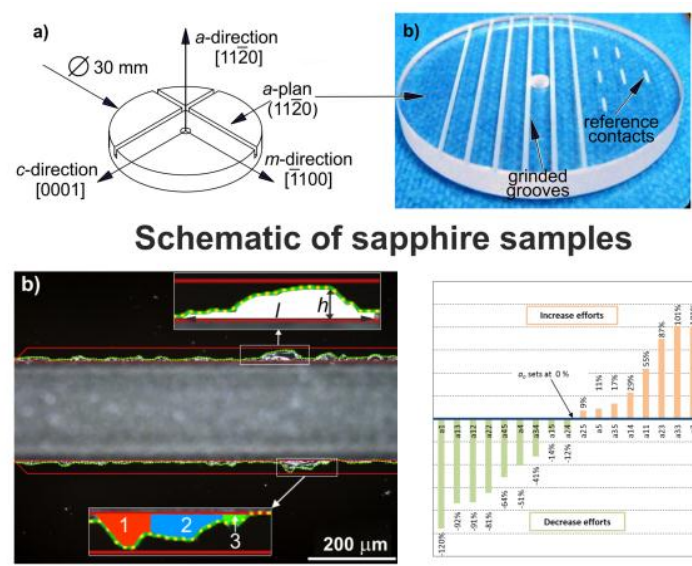

Defects analysis

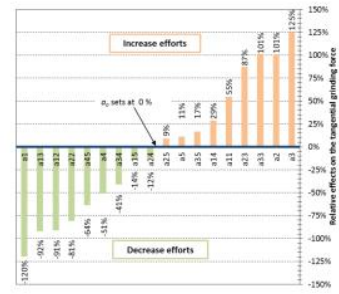

DoE grinding model 